\title{
Diagnostic value of serum miR197 and miR145 in non-small cell lung cancer
}

\author{
ANKUI SUI ${ }^{1}$, XIFENG ZHANG ${ }^{2}$ and QING ZHU ${ }^{2}$ \\ ${ }^{1}$ Department of Oncology, Jimo Hospital of Traditional Chinese Medicine; ${ }^{2}$ Department of Infectious Disease, \\ The People's Hospital of Jimo District, Qingdao, Shandong 266200, P.R. China
}

Received November 2, 2018; Accepted January 14, 2019

DOI: $10.3892 / \mathrm{ol} .2019 .9958$

\begin{abstract}
Diagnostic value of microRNA (miR)-197 and miR-145 in non-small cell lung cancer (NSCLC) and their relationship with the clinicopathological parameters of NSCLC patients were investigated. Seventy-six patients with NSCLC admitted to Jimo Hospital of Traditional Chinese Medicine from July 2016 to March 2018 were enrolled in group A, while 60 healthy who received health examinations during the same period were enrolled in group B. The relative expression levels of serum miR-197 and miR-145 were detected by RT-qPCR. The relative expression of serum miR-197 in group A was significantly higher than that in group $\mathrm{B}(\mathrm{P}<0.001)$; the relative expression of serum miR-145 in group A was significantly lower than that in group $\mathrm{B}(\mathrm{P}<0.001)$; serum miR-197 in group A showed association with the clinical stage of NSCLC patients $(\mathrm{P}<0.001)$; serum miR-145 in group A was associated with the clinical stage and pathological differentiation of patients with NSCLC $(\mathrm{P}<0.001)$. The AUC of serum miR-197 diagnosis of NSCLC was 0.864 (95\% CI: 0.804-0.924), with a diagnostic sensitivity of $73.68 \%$ and a specificity of $85.00 \%$; the AUC of serum miR-145 diagnosis of NSCLC was 0.879 (95\% CI: 0.824-0.934), with a diagnostic sensitivity of $84.21 \%$ and a specificity of $71.67 \%$; the AUC of the diagnosis of the combination of serum miR-197 and miR-145 for NSCLC was 0.952 (95\% CI: 0.919-0.984), with a diagnostic sensitivity of $92.10 \%$ and a specificity of $78.33 \%$. miR-197 and miR-145 are potential new biomarkers in the diagnosis of NSCLC due to their possible involvement in the occurrence and development of NSCLC. With good sensitivity and specificity of single miR-197 and single miR-145 for the diagnosis of NSCLC, the combined detection of miR-197 and miR-145 can achieve a better sensitivity in the diagnosis of NSCLC.
\end{abstract}

Correspondence to: Dr Ankui Sui, Department of Oncology, Jimo Hospital of Traditional Chinese Medicine, 1281 Lanao Road, Qingdao, Shandong 266200, P.R. China

E-mail: sn47qn@163.com

Key words: non-small cell lung cancer, miR-197, miR-145, clinicopathological parameters, diagnostic value

\section{Introduction}

Lung cancer is a lethal malignant tumor with a high mortality rate. Its morbidity and mortality rates are on the increase (1). Patients with non-small cell lung cancer (NSCLC) account for $\sim 85 \%$ of all lung cancer patients. According to the World Health Organization, the number of lung cancer cases exceeds $1,605,000$ cases/year, and the number of deaths caused by lung cancer accounts for $\sim 18.2 \%$ of all deaths resulted from malignant tumors (2). The few obvious symptoms of patients with early NSCLS make it hard to perform a timely and correct diagnosis. At present, the treatment of NSCLC is still a thorny clinical problem. Although the treatment of early NSCLC has made great progress and patients with NSCLC at the IA tumor stage can achieve a good prognosis after the surgical resection, with a 5-year survival rate of $83.9 \%$, most NSCLC patients cannot get a correct diagnosis until reaching the advanced stage, thus, achieving a poor overall survival rate $(3,4)$. The correct diagnosis in the early stage together with a timely treatment can reduce the mortality of NSCLC patients.

Tissue cell biopsy, the gold standard for the diagnosis of NSCLC, is a traumatic examination and is difficult to practice since tumor tissues generally are not easily available in the clinic (5). Despite the ability of imaging CT scan and chest X-ray examination to detect early NSCLC, CT scan screening brings a high rate of false-positive results which may cause a psychological anxiety of patients, resulting in unnecessary histological examination or surgery $(6,7)$. Considering this, the search for minimally invasive biological markers closely related to the early diagnosis of NSCLC is of great significance for the timely diagnosis and treatment of NSCLC.

MicroRNA (miR), an endogenous small molecule non-coding RNA with a length of 19-22 nucleotides, is a class of highly conserved non-protein-coding RNAs involved in the regulation of gene expression (8). In mammals, single-stranded miRs can inhibit the translation or promote the degradation of mRNA by binding to a complementary target sequence on a particular mRNA [usually the 3' untranslated region (3'UTR)] (9). More than half of $\mathrm{miR}$ genes are located in cancer-associated genomic regions, and stable miR molecules can be detected in peripheral blood, in close relation to cancer diagnosis, treatment, and prognosis (10). miR-197 and miR-145 are abnormally expressed in NSCLC and play different roles. For example, Mavridis et al (11) have identified the expression of miR-197 
as an independent predictor of poor prognosis in patients with NSCLC. Skjefstad et al (12) have pointed out the role of miR-145 in lung cancer as a tumor suppressor molecule and have discovered that it can be used as a biological indicator for the targeted therapy of NSCLC.

At present, few studies on the diagnosis of NSCLC by serum miR-197 and miR-145 have been reported. The present study investigated the expression of miR-197 and miR-145 in the serum of NSCLC patients and explored the diagnostic value of miR-197 and miR-145 and their relationship with the clinicopathological features of NSCLC.

\section{Patients and methods}

General information. Seventy-six patients with NSCLC admitted to Jimo Hospital of Traditional Chinese Medicine (Qingdao, China) from July 2016 to March 2018 were enrolled in group $\mathrm{A}$, including 49 males and 27 females, aged from 42 to 73 years, with an average age of $57.61 \pm 9.83$ years. Group A was divided into 41 patients in clinical stage I-II and 35 patients in stage III-IV; or divided into 45 highly and moderately differentiated patients and 31 poorly differentiated patients, according to pathological differentiation; or divided into 48 patients with lymph node metastasis and 28 patients without lymph node metastasis. Inclusion criteria: subjects confirmed by pathology, cytology, and imaging as NSCLC patients (13); patients with no radiotherapy, chemotherapy, or immunotherapy before surgery; patients with complete clinical data. Exclusion criteria: patients with NSCLC complicated with either cardiopulmonary dysfunction, or severe liver and kidney dysfunction, or connective tissue disease, or endocrine and metabolic diseases, or neurological diseases, or hematopoietic disorder, or immunological diseases; patients with mental illness or a family history of mental illness. Sixty healthy volunteers who received health examinations during the same period were enrolled in group B, including 34 males and 26 females, aged from 31 to 75 years, with an average age of $58.34 \pm 10.3$ years. All the research subjects and/or their families signed an informed consent after having received details of this study, which was approved by the Ethics Committee of Jimo Hospital of Traditional Chinese Medicine.

Main instruments and reagents. ABI Prism 7500 fluorescence quantitative PCR instrument (Applied Biosystems; Thermo Fisher Scientific, Inc., Waltham, MA, USA); TRIzol kit (Shanghai Enzyme-linked Biotechnology Co., Ltd., Shanghai, China); TRIzol Plus RNA purification kit [Thermo Fisher Scientific (China) Co., Ltd., Shanghai, China]; M-MLV Reverse Transcription kit (Applied Biosystems; Thermo Fisher Scientific, Inc.); microRNA PCR Premix kit (JRDUN Biotechnology Co., Ltd., Shanghai, China); UV-Vis Spectrophotometer (Bio-Rad Laboratories, Inc., Hercules, CA, USA). The internal reference primers of miR-197, miR-145, and U6 were designed and synthesized by Shanghai Haling Biotechnology Co., Ltd. (Shanghai, China). The sequences of required primers are shown in Table I.

RT-qPCR detection. Fasting venous blood $(5 \mathrm{ml})$ was taken from the participants in the two groups and was placed in an EDTA-K2 anticoagulation tube for $20 \mathrm{~min}$ of centrifugation at $2,600 \mathrm{x}$ g at $22^{\circ} \mathrm{C}$. Then, $500 \mu \mathrm{l}$ of the upper serum was collected and stored in an EP tube. The extraction of serum total RNA was performed with reference to the manufacturer's instructions of TRIzol Plus RNA purification kit. The absorbance of the RNA was measured using an ultraviolet-visible spectrophotometer and the concentration was calculated. Then, $2 \mu \mathrm{l}$ of total RNA were transcribed into cDNA according to the manufacturer's instructions of the M-MLV Reverse Transcription kit. The reverse transcription reaction system was: $42^{\circ} \mathrm{C}$ for $60 \mathrm{~min}$ and $95^{\circ} \mathrm{C}$ for $5 \mathrm{~min}$ and the synthesized cDNA sample was stored at $-20^{\circ} \mathrm{C}$. The total volume of the reaction system of U6 as the internal reference gene was $20 \mu \mathrm{l}$ : $10 \mu 1$ of microRNA PCR Premix, $2 \mu 1$ of forward primer (10X), $2 \mu$ l of reverse primer (10X), and enough $\mathrm{ddH}_{2} \mathrm{O}$ (RNAse/DNAse free) to increase the whole reaction system up to $20 \mu \mathrm{l}$. Conditions for PCR amplification: 40 cycles for $90^{\circ} \mathrm{C}$ for $5 \mathrm{~min}, 90^{\circ} \mathrm{C}$ for $5 \mathrm{sec}, 60^{\circ} \mathrm{C}$ for $30 \mathrm{sec}$, and $72^{\circ} \mathrm{C}$ for $5 \mathrm{sec}$. Finally, the ABI PRISM 7500 fluorescence quantitative PCR instrument was used for the analysis of amplification data, and the results were shown using the $2^{-\mathrm{ACq}}$ method (14).

Statistical analysis. Statistical analysis was performed using SPSS 19.0 software (IBM Corp., Armonk, NY, USA). Count data were expressed as [n (\%)] and measurement data as mean \pm standard deviation (mean $\pm \mathrm{SD}$ ). Chi-square test was used for the comparison of count data between groups; t-test was used for the comparison of measurement data between groups; receiver operating characteristic (ROC) curves were drawn to evaluate the efficiency of miR-197 and miR-145 in the diagnosis of NSCLC. $\mathrm{P}<0.05$ was considered to indicate a a statistically significant difference.

\section{Results}

General information. No statistical difference was detected between groups A and B in general clinical data, including sex, age, body mass index, smoking history, drinking history, blood glucose (Glu), hemoglobin (Hb), alanine transaminase (ALT), aspartate transaminase (AST), red blood cell (RBC) count, and platelet (PLT) count $(\mathrm{P}>0.05)$ (Table II).

Relative expression levels of serum miR-197 in the two groups. The relative expression level of serum miR-197 in group A was $4.16 \pm 0.43$, much higher than that in group B $(1.08 \pm 0.26)$ $(\mathrm{t}=48.860, \mathrm{P}<0.001)$ (Fig. 1).

Relative expression levels of serum miR-145 in the two groups. The relative expression level of serum miR-145 in group A was $1.03 \pm 0.37$, greatly lower than that in group B $(1.26 \pm 0.42)$ $(\mathrm{t}=3.391, \mathrm{P}<0.001)$ (Fig. 2).

The relationship of the relative expression levels of serum miR-197 and miR-145 in group A with the clinicopathological features of patients with NSCLC. Serum miR-197 in group A was not associated with clinicopathological features of NSCLC patients, such as sex, age, smoking history, pathological differentiation, lymph node metastasis, and the diameter of the tumor $(\mathrm{P}>0.05)$, but was associated with clinical stage $(\mathrm{P}<0.001)$. Serum miR-145 in group A was not related with the clinicopathological features of sex, age, smoking history, 
Table I. Primer sequences of miR-197, miR-145, and U6.

\begin{tabular}{lll}
\hline Gene & \multicolumn{1}{c}{ Forward primers } & \multicolumn{1}{c}{ Reverse primers } \\
\hline miR-197 & 5'-ATTACTTTGCCCATATTCATTTTGA-3' & 5'-ATTCTAGAGGCCGAGGCGGCCGACATGT-3' \\
miR-145 & 5'-CAGTGCGTGTCGTGGAGT-3' & 5'-AGGTCCAGTTTTCCCAGG-3' \\
U6 & 5'-CTCGCTTCGGCAGCACA-3' & 5'-AACGCTTCACGAATTTGCGT-3' \\
\hline
\end{tabular}

Table II. General information of groups A and B [n (\%) or mean \pm SD].

\begin{tabular}{|c|c|c|c|c|}
\hline Factor & Group A $(n=76)$ & Group B $(n=60)$ & $\mathrm{t} / \chi^{2}$ value & P-value \\
\hline Sex & & & 0.859 & 0.354 \\
\hline Male & $49(64.47)$ & $34(56.67)$ & & \\
\hline Female & $27(35.53)$ & $26(43.33)$ & & \\
\hline Age (years) & $57.61 \pm 9.83$ & $58.34 \pm 10.3$ & 0.428 & 0.670 \\
\hline Body mass index $\left(\mathrm{kg} / \mathrm{m}^{2}\right)$ & $18.94 \pm 3.06$ & $19.37 \pm 2.95$ & & \\
\hline Smoking & & & 3.620 & 0.057 \\
\hline Yes & $39(51.32)$ & $21(35.00)$ & & \\
\hline No & $37(48.68)$ & $39(65.00)$ & & \\
\hline Drinking & & & 0.887 & 0.346 \\
\hline Yes & $30(39.47)$ & $19(31.67)$ & & \\
\hline No & $46(60.53)$ & $41(68.33)$ & & \\
\hline Glu (mmol/l) & $5.98 \pm 0.57$ & $6.07 \pm 0.43$ & 1.016 & 0.312 \\
\hline $\mathrm{Hb}(\mathrm{gm} / \mathrm{dl})$ & $14.45 \pm 0.98$ & $14.68 \pm 0.86$ & 1.433 & 0.154 \\
\hline $\operatorname{ALT}(\mathrm{U} / \mathrm{l})$ & $21.05 \pm 9.14$ & $22.47 \pm 9.53$ & 0.883 & 0.379 \\
\hline $\operatorname{AST}(\mathrm{U} / \mathrm{l})$ & $19.27 \pm 7.09$ & $18.49 \pm 7.57$ & 0.618 & 0.538 \\
\hline $\mathrm{RBC}\left(\mathrm{x} 10^{12} / 1\right)$ & $4.29 \pm 0.48$ & $4.23 \pm 0.37$ & 0.799 & 0.426 \\
\hline $\operatorname{PLT}\left(\times 10^{9} / 1\right)$ & $153.75 \pm 18.37$ & $159.08 \pm 21.37$ & 1.563 & 0.120 \\
\hline
\end{tabular}

SD, standard deviation; Glu, glucose; Hb, hemoglobin; ALT, alanine transaminase; AST, aspartate transaminase; RBC, red blood cell; PLT, platelet.

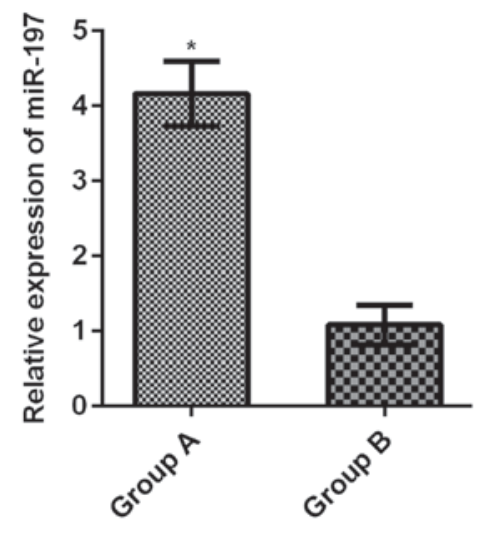

Figure 1. Comparison of the relative expression levels of serum miR-197 between the two groups. The RT-qPCR results showed that the relative expression of serum miR-197 in group A was significantly higher than that in group $\mathrm{B}\left(\mathrm{t}=48.860,{ }^{*} \mathrm{P}<0.001\right)$.

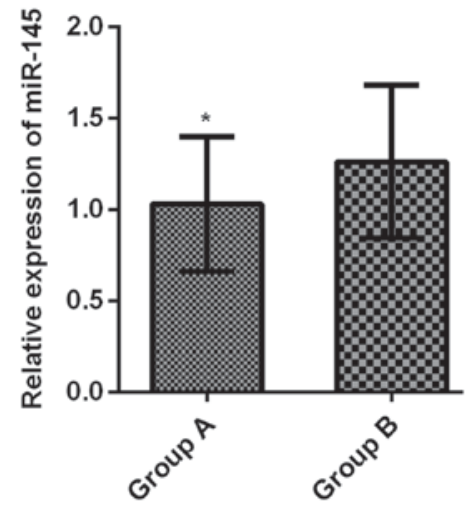

Figure 2. Comparison of the relative expression levels of serum miR-145 between the two groups. According to the RT-qPCR results, the relative expression of serum miR-145 in group A was significantly lower than that in group $\mathrm{B}\left(\mathrm{t}=3.391,{ }^{*} \mathrm{P}<0.001\right)$. lymph node metastasis, and the diameter of the tumor in NSCLC patients $(\mathrm{P}>0.05)$, was associated with the clinical stage and pathological differentiation $(\mathrm{P}<0.001)$ (Table III).
Diagnostic value of the relative expression levels of serum miR-197, miR-145, and their combination for NSCLC. According to the ROC curves for the diagnosis of the 
Table III. Relationship of the relative expression levels of serum miR-197 and miR-145 in group A with the clinicopathological features of patients with NSCLC (mean \pm SD).

\begin{tabular}{|c|c|c|c|c|c|c|c|}
\hline Clinicopathological feature & $\mathrm{n}$ & miR-197 & t value & P-value & $\operatorname{miR}-145$ & t value & P-value \\
\hline Sex & & & 0.974 & 0.333 & & 0.803 & 0.425 \\
\hline Male & 49 & $4.18 \pm 0.51$ & & & $1.12 \pm 0.27$ & & \\
\hline Female & 27 & $4.07 \pm 0.39$ & & & $1.07 \pm 0.24$ & & \\
\hline Age (years) & & & 1.360 & 0.178 & & 1.712 & 0.091 \\
\hline$<60$ & 30 & $4.04 \pm 0.45$ & & & $1.15 \pm 0.31$ & & \\
\hline$\geq 60$ & 46 & $4.21 \pm 0.58$ & & & $1.03 \pm 0.28$ & & \\
\hline Smoking & & & 0.937 & 0.352 & & 1.223 & 0.225 \\
\hline Yes & 39 & $4.19 \pm 0.54$ & & & $1.17 \pm 0.29$ & & \\
\hline No & 37 & $4.08 \pm 0.48$ & & & $1.08 \pm 0.35$ & & \\
\hline Clinical stage & & & 14.290 & $<0.001$ & & 9.360 & $<0.001$ \\
\hline Stage I-II & 41 & $3.45 \pm 0.49$ & & & $1.39 \pm 0.30$ & & \\
\hline Stage III-IV & 35 & $5.27 \pm 0.62$ & & & $0.84 \pm 0.21$ & & \\
\hline Pathological differentiation & & & 1.203 & 0.233 & & 8.263 & $<0.001$ \\
\hline Highly and moderately differentiated & 45 & $4.11 \pm 0.36$ & & & $1.28 \pm 0.32$ & & \\
\hline Poorly differentiated & 31 & $4.23 \pm 0.51$ & & & $0.75 \pm 0.19$ & & \\
\hline Lymph node metastasis & & & 1.704 & 0.093 & & 1.554 & 0.125 \\
\hline Yes & 48 & $4.26 \pm 0.37$ & & & $1.04 \pm 0.22$ & & \\
\hline No & 28 & $4.08 \pm 0.55$ & & & $1.13 \pm 0.28$ & & \\
\hline Diameter of the tumor $(\mathrm{cm})$ & & & 0.491 & 0.625 & & 1.477 & 0.144 \\
\hline$\leq 5$ & 45 & $4.14 \pm 0.46$ & & & $1.17 \pm 0.36$ & & \\
\hline$>5$ & 31 & $4.19 \pm 0.40$ & & & $1.05 \pm 0.33$ & & \\
\hline
\end{tabular}

NSCLC, non-small cell lung cancer; SD, standard deviation.

Table IV. Diagnostic value of the relative expression levels of serum miR-197, miR-145, and their combination in NSCLC.

\begin{tabular}{lcccccc}
\hline Indicator for diagnosis & AUC & $95 \%$ CI & SD & Cut-off value & Sensitivity (\%) & Specificity (\%) \\
\hline miR-197 & 0.864 & $0.804-0.924$ & 0.031 & 3.260 & 73.68 & 85.00 \\
miR-145 & 0.879 & $0.824-0.934$ & 0.028 & 1.098 & 84.21 & 71.67 \\
miR-197 + miR-145 & 0.952 & $0.919-0.984$ & 0.017 & 0.303 & 92.10 & 78.33
\end{tabular}

NSCLC, non-small cell lung cancer; SD, standard deviation.

relative expression levels of serum miR-197 and miR-145 on NSCLC, the AUC of serum miR-197 diagnosis of NSCLC was 0.864 (95\% CI: 0.804-0.924), with a cut-off value of 3.260 , a diagnostic sensitivity of $73.68 \%$, and a specificity of $85.00 \%$; the AUC of serum miR-145 diagnosis of NSCLC was 0.879 (95\% CI: 0.824-0.934), with a cut-off value of 1.098 , a diagnostic sensitivity of $84.21 \%$, and a specificity of $71.67 \%$. Another ROC curve was drawn for the diagnosis of the combination of serum miR-197 and miR-145 on NSCLC, and the results showed that the AUC of the diagnosis of the combination of serum miR-197 and miR-145 was 0.952 (95\% CI: 0.919-0.984), with a cut-off value of 0.303 , a diagnostic sensitivity of $92.10 \%$, and a specificity of 78.33 (Table IV and Fig. 3).

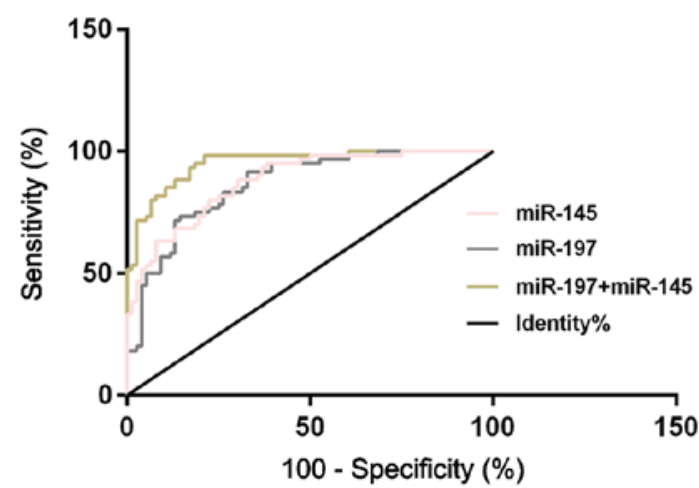

Figure 3. ROC curves of the relative expression levels of serum miR-197, miR-145, and their combination for the diagnosis of NSCLC. ROC, receiver operating characteristic; NSCLC, non-small cell lung cancer. 


\section{Discussion}

Lung cancer, a very common malignant tumor, has a morbidity and mortality rate that rank at the top of all malignant tumors $(15,16)$. Most lung cancer patients cannot get a correct diagnosis until they have reached the advanced stage, thus, they lose the best time for surgery and receive an unsatisfactory 5-year survival rate (17). This makes the improvement of the diagnosis rate and overall survival rate of lung cancer patients a knotty problem in the clinic. Histopathological biopsy, the gold standard for NSCLC diagnosis, has limited clinical application due to large trauma and difficulty in tissue collection. Therefore, the identification of non-traumatic serum tumor biomarkers for the diagnosis of NSCLC has become the focus of current research (18). Serum tumor markers, such as neuron-specific enolase, carbohydrate antigen, and carcinoembryonic antigen are currently applied to diagnose NSCLC $(19,20)$, but their sensitivity and specificity of detection are often unsatisfactory. Therefore, much attention has been devoted to the search for new serum tumor markers for the early diagnosis of NSCLC.

miRs, a class of highly conserved non-coding small RNAs that are widely distributed in eukaryotic cells, play an important role in the development and progression of malignant tumors, such as the capability of inhibiting the growth and metastasis of NSCLC cells by reducing the PTEN expression as reported by Xie et al (21). Due to the access of miR to the blood circulatory system, the miR expression level in the tumor tissue can be reflected to some extent by the expression level of $\mathrm{miR}$ in the blood which plays an important role in the early diagnosis, development and prognosis evaluation of tumors $(22,23)$. The role of miR-197 in cancers has been extensively studied. Fiori et al (24) have considered NOXA and BMF as target drones of miR-197 and have shown that they could induce apoptosis of p53 wild-type cells. Moreover, Yang et al (25) have suggested that miR-197 can induce cell apoptosis and inhibit carcinogenicity by targeting MCL-1 in multiple myelomas. miR-145, located on chromosome 5 , has an abnormal expression in a variety of tumors, such as esophagus cancer, hepatocellular carcinoma, breast cancer, and gastric cancer $(26,27)$. Mo et al (28) have found that miR-145 could inhibit the invasion and migration of lung adenocarcinoma cells by targeting $\mathrm{N}$-cadherin.

The results of this study revealed that the relative expression of serum miR-197 in NSCLC patients (group A) is significantly higher than that in healthy subjects (group B); group A has a much lower relative expression of serum miR-145 than group B; the serum miR-197 in group A is related to the clinical stage of NSCLC patients; serum miR-145 is associated with clinical stage and pathological differentiation in patients with NSCLC. Such results indicate that miR-197 and miR-145 may be involved in the occurrence and development of NSCLC, with a possible tumor-promoting function of miR-197 and a potential tumor-suppressing function of miR-145. Du et al (29) have found that miR-197, with a greatly increased expression level in NSCLC, could inhibit the expression of the tumor suppressor gene FUS1. Shen et al (30) have confirmed in their study that the low expression level of miR-145 is closely related to the poor pathological differentiation and prognosis of NSCLC. Therefore, miR-197 and miR-145 are certainly involved in the development and progression of NSCLC to some extent, capable of serving as therapeutic targets and biomarkers of NSCLC. According to the results of the present study, serum miR-197 has a sensitivity of $73.68 \%$ and a specificity of $85.00 \%$ in diagnosing NSCLC; serum miR-145 has a sensitivity of $84.21 \%$ and a specificity of $71.67 \%$; the combination of serum miR-197 and miR-145 has a sensitivity of $92.10 \%$ and a specificity of $78.33 \%$, suggesting an improved diagnostic sensitivity by the combined detection and a possibility that miR-197 and miR-145 can be used as biological indicators to diagnose NSCLC with good sensitivity and specificity. miR-197 has been proven to work as a biological indicator for breast cancer screening in the study by Shaker et al (31), and miR-145 has been shown to function as a biomarker for the detection of ovarian cancer and other human cancers in the study by Liang et al (32). Such studies confirm the capability of miR-197 and miR-145 to be used as diagnostic biomarkers of NSCLC. However, considering the clinical basis for the diagnosis of NSCLC, cytology and histopathology, the tumor markers of the blood circulation system cannot be used as the standard for the diagnosis of NSCLC. Therefore, the detection of serum miR can work as an early warning of NSCLC for patients in the early tumor stage without clear clinical symptoms, improving the screening and early diagnosis of lung cancer when combined with imaging examinations.

This study confirmed the diagnostic value of miR-197 and miR-145 in NSCLC, but with some limitations. For example, in this study the role of miR-197 and miR-145 in the prognosis of NSCLC patients was not observed, and research on the regulatory mechanisms of the two in NSCLC cells was not conducted. These will be the aim of our future research in order to improve and provide further evidence for this study.

In summary, miR-197 and miR-145 show potential as new biomarkers for the diagnosis of NSCLC due to their possible involvement in the occurrence and development of NSCLC. With good sensitivity and specificity of single miR-197 and single miR-145, the combined detection of miR-197 and miR-145 can achieve a better sensitivity in the diagnosis of NSCLC.

\section{Acknowledgements}

Not applicable.

\section{Funding}

No funding was received.

\section{Availability of data and materials}

The datasets used and/or analyzed during the present study are available from the corresponding author on reasonable request.

\section{Authors' contributions}

AS interpreted the data and drafted the manuscript. XZ and QZ acquired and analyzed the general data of patients. AS and QZ performed PCR. All authors read and approved the final manuscript. 


\section{Ethics approval and consent to participate}

The study was approved by the Ethics Committee of Jimo Hospital of Traditional Chinese Medicine (Qingdao, China). Patients who participated in this research, signed the informed consent and had complete clinical data. Signed written informed consents were obtained from the patients and/or guardians.

\section{Patient consent for publication}

Not applicable.

\section{Competing interests}

The authors declare that they have no competing interests.

\section{References}

1. Torre LA, Bray F, Siegel RL, Ferlay J, Lortet-Tieulent J and Jemal A: Global cancer statistics, 2012. CA Cancer J Clin 65: 87-108, 2015.

2. Hou J, Meng F, Chan LW, Cho WC and Wong SC: Circulating plasma microRNAs as diagnostic markers for NSCLC. Front Genet 7: 193, 2016.

3. Zhu W, Zhou K, Zha Y, Chen D, He J, Ma H, Liu X, Le H and Zhang Y: Diagnostic value of serum miR-182, miR-183, miR-210, and miR-126 levels in patients with early-stage non-small cell lung cancer. PLoS One 11: e0153046, 2016.

4. Scagliotti GV, Fossati R, Torri V, Crinò L, Giaccone G, Silvano G, Martelli M, Clerici M, Cognetti F and Tonato M; Adjuvant Lung Project Italy/European Organisation for Research Treatment of Cancer-Lung Cancer Cooperative Group Investigators: Randomized study of adjuvant chemotherapy for completely resected stage I, II, or IIIA non-small-cell lung cancer. J Natl Cancer Inst 95: 1453-1461, 2003.

5. Navani N, Nankivell M, Lawrence DR, Lock S, Makker H, Baldwin DR, Stephens RJ, Parmar MK, Spiro SG, Morris S, et al; Lung-BOOST trial investigators: Lung cancer diagnosis and staging with endobronchial ultrasound-guided transbronchial needle aspiration compared with conventional approaches: An open-label, pragmatic, randomised controlled trial. Lancet Respir Med 3: 282-289, 2015.

6. Bonatti M, Vezzali N,Lombardo F, Ferro F, Zamboni G, Tauber M and Bonatti G: Gallbladder adenomyomatosis: Imaging findings, tricks and pitfalls. Insights Imaging 8: 243-253, 2017.

7. Aberle DR, Adams AM, Berg CD, Black WC, Clapp JD, Fagerstrom RM, Gareen IF, Gatsonis C, Marcus PM and Sicks JD; National Lung Screening Trial Research Team: Reduced lung-cancer mortality with low-dose computed tomographic screening. N Engl J Med 365: 395-409, 2011.

8. Ha M and Kim VN: Regulation of microRNA biogenesis. Nat Rev Mol Cell Biol 15: 509-524, 2014.

9. Mehta AK, Hua K, Whipple W, Nguyen MT, Liu CT, Haybaeck J, Weidhaas J, Settleman J and Singh A: Regulation of autophagy, $\mathrm{NF}-\kappa \mathrm{B}$ signaling, and cell viability by miR-124 in KRAS mutant mesenchymal-like NSCLC cells. Sci Signal 10: 10, 2017.

10. Wang RJ, Zheng YH, Wang P and Zhang JZ: Serum miR-125a-5p, miR-145 and miR-146a as diagnostic biomarkers in non-small cell lung cancer. Int J Clin Exp Pathol 8: 765-771, 2015.

11. Mavridis K, Gueugnon F, Petit-Courty A, Courty Y, Barascu A, Guyetant S and Scorilas A: The oncomiR miR-197 is a novel prognostic indicator for non-small cell lung cancer patients. Br J Cancer 112: 1527-1535, 2015.

12. Skjefstad K, Johannessen C, Grindstad T, Kilvaer T, Paulsen EE, Pedersen M, Donnem T, Andersen S, Bremnes R, Richardsen E, et al: A gender specific improved survival related to stromal miR-143 and miR-145 expression in non-small cell lung cancer. Sci Rep 8: 8549, 2018.

13. Novello S, Barlesi F, Califano R, Cufer T, Ekman S, Levra MG, Kerr K, Popat S, Reck M, Senan S, et al; ESMO Guidelines Committee: Metastatic non-small-cell lung cancer: ESMO Clinical Practice Guidelines for diagnosis, treatment and follow-up. Ann Oncol 27 (Suppl 5): v1-v27, 2016.
14. Livak KJ and Schmittgen TD: Analysis of relative gene expression data using real-time quantitative PCR and the 2(-Delta Delta C(T)) method. Methods 25: 402-408, 2001.

15. Guisier F, Salaün M, Lachkar S, Lamy A, Piton N, Obstoy B, Sabourin JC and Thiberville L: Molecular analysis of peripheral non-squamous non-small cell lung cancer sampled by radial EBUS. Respirology 21: 718-726, 2016.

16. Torre LA, Siegel RL and Jemal A: Lung cancer statistics. Adv Exp Med Biol 893: 1-19, 2016.

17. Montani F, Marzi MJ, Dezi F, Dama E, Carletti RM, Bonizzi G, Bertolotti R, Bellomi M, Rampinelli C, Maisonneuve P, et al: miR-Test: A blood test for lung cancer early detection. J Natl Cancer Inst 107: djv063, 2015.

18. Yang JS, Li BJ, Lu HW, Chen Y, Lu C, Zhu RX, Liu SH, Yi QT, Li J and Song CH: Serum miR-152, miR-148a, miR-148b, and miR-21 as novel biomarkers in non-small cell lung cancer screening. Tumour Biol 36: 3035-3042, 2015.

19. Molina R, Marrades RM, Augé JM, Escudero JM, Viñolas N, Reguart N, Ramirez J, Filella X, Molins L and Agustí A: Assessment of a combined panel of six serum tumor markers for lung cancer. Am J Respir Crit Care Med 193: 427-437, 2016.

20. Holdenrieder S, von Pawel J, Dankelmann E, Duell T, Faderl B, Markus A, Siakavara M, Wagner H, Feldmann K, Hoffmann H, et al: Nucleosomes, ProGRP, NSE, CYFRA 21-1, and CEA in monitoring first-line chemotherapy of small cell lung cancer. Clin Cancer Res 14: 7813-7821, 2008.

21. Xie X, Liu HT, Mei J, Ding FB, Xiao HB, Hu FQ, Hu R and Wang MS: miR-106a promotes growth and metastasis of non-small cell lung cancer by targeting PTEN. Int J Clin Exp Pathol 8: 3827-3834, 2015.

22. Nadal E, Truini A, Nakata A, Lin J, Reddy RM, Chang AC, Ramnath N, Gotoh N, Beer DG and Chen G: A novel serum 4-microRNA signature for lung cancer detection. Sci Rep 5: 12464, 2015.

23. Zuberi M, Khan I, Mir R, Gandhi G, Ray PC and Saxena A: Utility of serum miR-125b as a diagnostic and prognostic indicator and its alliance with a panel of tumor suppressor genes in epithelial ovarian cancer. PLoS One 11: e0153902, 2016.

24. Fiori ME, Barbini C, Haas TL, Marroncelli N, Patrizii M, Biffoni M and De Maria R: Antitumor effect of miR-197 targeting in p53 wild-type lung cancer. Cell Death Differ 21: 774-782, 2014.

25. Yang Y, Li F, Saha MN, Abdi J, Qiu L and Chang H: miR-137 and miR-197 induce apoptosis and suppress tumorigenicity by targeting MCL-1 in multiple myeloma. Clin Cancer Res 21: 2399-2411, 2015.

26. Pekow J, Meckel K, Dougherty U, Butun F, Mustafi R, Lim J, Crofton C, Chen X, Joseph L and Bissonnette M: Tumor suppressors miR-143 and miR-145 and predicted target proteins API5, ERK5, K-RAS, and IRS-1 are differentially expressed in proximal and distal colon. Am J Physiol Gastrointest Liver Physiol 308: G179-G187, 2015.

27. Xie H, Ren X, Xin S, Lan X, Lu G, Lin Y, Yang S, Zeng Z, Liao W, Ding YQ, et al: Emerging roles of circRNA_001569 targeting miR-145 in the proliferation and invasion of colorectal cancer. Oncotarget 7: 26680-26691, 2016.

28. Mo D, Yang D, Xiao X, Sun R, Huang L and Xu J: MiRNA-145 suppresses lung adenocarcinoma cell invasion and migration by targeting N-cadherin. Biotechnol Lett 39: 701-710, 2017.

29. Du L, Schageman JJ, Subauste MC, Saber B, Hammond SM, Prudkin L, Wistuba II, Ji L, Roth JA, Minna JD, et al: miR-93, miR-98, and miR-197 regulate expression of tumor suppressor gene FUS1. Mol Cancer Res 7: 1234-1243, 2009.

30. Shen H, Shen J, Wang L, Shi Z, Wang M, Jiang BH and Shu Y: Low miR-145 expression level is associated with poor pathological differentiation and poor prognosis in non-small cell lung cancer. Biomed Pharmacother 69: 301-305, 2015.

31. Shaker O, Maher M, Nassar Y, Morcos G and Gad Z: Role of microRNAs $-29 b-2,-155,-197$ and -205 as diagnostic biomarkers in serum of breast cancer females. Gene 560: 77-82, 2015.

32. Liang H, Jiang Z, Xie G and Lu Y: Serum microRNA-145 as a novel biomarker in human ovarian cancer. Tumour Biol 36: 5305-5313, 2015.

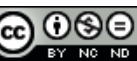

This work is licensed under a Creative Commons Attribution-NonCommercial-NoDerivatives 4.0 International (CC BY-NC-ND 4.0) License. 